\title{
Efficacy of Repetitive Transcranial Magnetic
}

\section{Stimulation Combined with Botulinum Toxin Type A for Benign Essential Blepharospasm Patients Accompanied by Anxiety and Depression}

Bo Yin

Bin Peng

Ying Luo

Shanghua Fan (D)

Ting Xiao

Xiaoli Zou

Hongjuan Dong

Department of Neurology, Renmin Hospital of Wuhan University, Wuhan, 430060, People's Republic of China
Correspondence: Hongjuan Dong Department of Neurology, Renmin Hospital of Wuhan University, 99

Zhangzhidong Road, Wuchang District, Wuhan, 430060, People's Republic of China

Tel +86-27-88999l20

Email dhjdhj027@sina.com
Objective: To evaluate the improvement of motor, anxiety, and depression in patients with blepharospasm with the use of botulinum toxin type A (BTX-A) and repetitive transcranial magnetic stimulation (rTMS).

Methods: A total of 63 BEB patients accompanied by anxiety/depression were enrolled, among which 28 patients were treated with the injection of botulinum toxin type A (BTX-A) alone, while 35 patients were treated with BTX-A injection combined with rTMS. All patients were followed up for 6 months, and the overall efficacy was evaluated.

Results: BTX-A alone treatment and combined rTMS treatment could both significantly improve the symptoms of patients, and the effective rate was $92.86 \%$ and $94.29 \%$, respectively. The duration of efficacy was significantly longer in the combined rTMS treatment group (16.89 \pm 3.39 weeks) than in BTX-A treatment group (13.04 \pm 3.48 weeks). After treatment, SDS score of BTX-A treatment group and combined rTMS treatment group was $49.69 \pm 7.90$ and $49.46 \pm 6.73$, respectively, and there was no significant difference between the two treatment groups; SAS score of BTX-A treatment group and combined rTMS treatment group was $53.88 \pm 7.34$ and $48.79 \pm 6.62$, respectively, and there was significant difference between the two treatment groups.

Conclusion: Compared to BTX-A alone treatment, BTX-A combined with rTMS can effectively improve the effect of BTX-A, prolong the duration of blepharospasm relief, and significantly reduce depression and anxiety in patients with BEB.

Keywords: botulinum toxin type A, repetitive transcranial magnetic stimulation, anxiety/ depression disorder, benign essential blepharospasm

\section{Introduction}

Benign essential blepharospasm (BEB) is a focal dystonia characterized by involuntary abnormal contraction of the orbicularis oculi muscle. ${ }^{1}$ Although blepharospasm is a benign disease, the involuntary contraction of eyelid muscles causes eye discomfort, fatigue, difficulty in opening eyes, and even functional blindness, which seriously affect the daily life of patients and may lead to anxiety and depression of the patients. At present, botulinum toxin type A (BTX-A) injection is the first-choice treatment option for blepharospasm. ${ }^{2}$ After BTX-A injection, more than $90 \%$ of the patients can significantly improve the motor symptoms of blepharospasm, and relieve the anxiety and depression of the patients. ${ }^{3}$ 
Transcranial magnetic stimulation (TMS) is a technique that uses pulsed magnetic fields to stimulate areas of the cerebral cortex. ${ }^{4}$ Repetitive transcranial magnetic stimulation (rTMS) is a stimulus mode in which multiple pulses are continuously emitted at a fixed frequency, and is a noninvasive neuromodulation treatment method. In clinical application, high-frequency or lowfrequency magnetic stimulation is used to excite or inhibit the function of specific cortical regions, and becomes an effective method to treat anxiety and depression. ${ }^{5}$ Blepharospasm can cause mood disorder, and mood disorder can also cause or aggravate blepharospasm. ${ }^{6}$ The aim of the study was to evaluate the improvement of motor, anxiety, and depression in patients with blepharospasm with the use of BTX-A and rTMS.

\section{Subjects and Methods Subjects}

A total of 63 BEB patients accompanied by anxiety and depression who visited our hospital from June 2017 to June 2018 were enrolled in this study. General information and medical history of all patients were collected, including the duration of illness, course of disease, medication history and family history. Neurological examination and SDS/SAS scoring were performed. Zong's Self-rating Anxiety Scale (SAS) and Zong's Self-rating Depression Scale (SDS) were used to assess anxiety and depression. After the patient's selfassessment, the total score was obtained by adding the scores of all items, and was multiplied by 1.25 to give the standard score. The SAS scale standard score $\geq 50$ indicated that the patient had anxiety symptoms; the SDS scale standard score $\geq 50$ indicated that the patient had depressive symptoms.

Inclusion criteria: 1) age 18-80 years; 2) meeting the BEB diagnostic criteria $;{ }^{7} 3$ ) SAS standard score $\geq 50$, and/ or SDS standard score $\geq 50 ; 4$ ) the patients were willing to cooperate with follow-up. Exclusion criteria: 1) secondary blepharospasm; 2) accompanied by other neurological symptoms or signs; 3 ) those who have undergone orbicularis oculi muscle resection. This study was approved by the Ethics Committee of Renmin Hospital of Wuhan University and was conducted in accordance with the Declaration of Helsinki. All patients signed informed consent before being enrolled in this study.

\section{Injection of BTX-A}

Botox dry powder (Allergan, USA, $100 \mathrm{U} / \mathrm{amp}$, approval No. S20070023) was diluted to $25 \mathrm{U} / \mathrm{mL}$ solution in
$2.5 \mathrm{~mL}$ sterile saline. The injection points were orbicularis oculi muscle, procerus, corrugator supercilii and frontal muscle, respectively, with a total injection dose of 25-75 $\mathrm{U}$. The patients were followed up for 6 months, those with more than $50 \%$ recurrence of symptoms were given a second injection after 3 months. During BTX-A treatment period, oral medications for BEB treatment were discontinued, including benzodiazepines, carbamazepine, gabapentin, benzhexol, and baclofen.

\section{Procedures of rTMS}

An 8-shaped coil transcranial magnetic stimulation instrument (Wuhan Yiruide Medical Equipment Co.) was used. The frequency was set to $1 \mathrm{~Hz}$, the stimulation time was set to $30 \mathrm{~s}$, the interval was $3 \mathrm{~s}$, and treatment time was 20 $\mathrm{min}$. The stimulation site was the dorsolateral area of the right frontal lobe, once a day for 10 consecutive days, with an interval of 5 days and then for 10 consecutive days.

\section{Follow-Up}

All patients were followed up for 6 months. The severity of BEB was graded according to the Cohen Albert criterion. ${ }^{8}$ The SAS and SDS scores were used to evaluate anxiety and depression before and 2 months after BTX-A injection. The efficacy was evaluated according to subjective feelings and blinking observation of the patients. The onset time of the first BTX-A treatment and the time interval from symptom recurrence were recorded. The efficacy was evaluated according to Cohen Albert grading, subjective feelings and blinking times of the patients, and was divided into complete remission, obvious remission, partial remission and ineffectiveness.

\section{Statistical Analysis}

SPSS 17.0 software was used for statistical analysis. The count data were analyzed using the chi-square $(\chi 2)$ test, and the measurement data were expressed as mean \pm standard deviation $(\mathrm{x} \pm \mathrm{s})$. The $t$-test was used to compare the difference between the groups. $\mathrm{P}<0.05$ indicated significant difference.

\section{Results}

General Data

Among 63 BEB patients accompanied by anxiety and depression, 28 patients received BTX-A treatment alone, and 35 patients received rTMS on the second day after BTX-A treatment. In BTX-A alone treatment group, there 
were 7 males and 21 females, with an average age of 56.27 \pm 4.65 years, an average onset age of $51.89 \pm 3.25$ years, and an average duration of $4.39 \pm 2.67$ years; the Cohen Albert criterion grading showed 0 case of grade I, 3 cases of grade II, 19 cases of grade III and 6 cases of grade IV. Total 18 cases received oral medication before treatment. In combined rTMS treatment group, there were 9 males and 26 females, with an average age of $55.09 \pm 4.44$ years, an average onset age of $50.91 \pm 2.90$ years, and an average duration of $4.17 \pm 2.91$ years. The Cohen Albert criterion grading showed 0 case of grade I, 2 cases of grade II, 28 cases of grade III and 5 cases of grade IV, among them, one case was complicated with oromandibular dystonia, and 21 cases received oral medication before treatment. There were no significant differences between the two groups (Table 1).

\section{Onset Time and Duration of Efficacy}

In BTX-A alone treatment group, 26 patients had complete remission/obvious remission, with an efficacy rate of $92.86 \%$. In combined rTMS treatment group, 33 patients had complete remission/obvious remission, with an efficacy rate of $94.29 \%$. There was no significant difference between the two groups (Table 2). The average onset time of efficacy in BTX-A alone treatment group was $4.93 \pm 2.72$ days, with no significant difference to that of the combined rTMS treatment group (4.26 \pm 2.34 days). The duration of efficacy was $13.04 \pm 3.48$ weeks in BTX-A alone group, but was $16.89 \pm 3.39$ weeks in combined rTMS treatment group, and the difference was significant between the two groups, indicating that combined rTMS treatment could prolong the duration of symptom relief (Table 3 ).

\section{Efficacy Evaluation}

SDS/SAS scores were used to evaluate the efficacy of the treatment. Before treatment, the SDS score of BTX-A

Table I General Information on Patients

\begin{tabular}{|l|l|l|l|}
\hline & $\begin{array}{l}\text { BTX-A } \\
\text { Group }\end{array}$ & $\begin{array}{l}\text { Combined rTMS } \\
\text { Group }\end{array}$ & P value \\
\hline Age (years) & $56.27 \pm 4.65$ & $55.09 \pm 4.44$ & 0.3008 \\
\hline Onset age (years) & $51.89 \pm 3.25$ & $50.91 \pm 2.90$ & 0.2121 \\
\hline $\begin{array}{l}\text { Course of disease } \\
\text { (years) }\end{array}$ & $4.39 \pm 2.67$ & $4.17 \pm 2.91$ & 0.7570 \\
\hline $\begin{array}{l}\text { Cohen grade } \\
\text { (median) }\end{array}$ & 3 & 3 & \\
\hline
\end{tabular}

Table 2 Overall Efficacy of Treatment

\begin{tabular}{|l|l|l|}
\hline & $\begin{array}{l}\text { Effective (Complete } \\
\text { Remission/Obvious } \\
\text { Remission) }\end{array}$ & $\begin{array}{l}\text { Ineffective (Partial } \\
\text { Remission/No } \\
\text { Remission) }\end{array}$ \\
\hline $\begin{array}{l}\text { BTX-A } \\
\text { group }\end{array}$ & 26 & 2 \\
\hline $\begin{array}{l}\text { Combined } \\
\text { rTMS } \\
\text { group }\end{array}$ & 33 & 2 \\
\hline
\end{tabular}

Table 3 Onset Time and Duration of Efficacy

\begin{tabular}{|l|l|l|l|}
\hline & $\begin{array}{l}\text { BTX-A } \\
\text { Group }\end{array}$ & $\begin{array}{l}\text { Combined rTMS } \\
\text { Group }\end{array}$ & P value \\
\hline $\begin{array}{l}\text { Onset time } \\
\text { (days) }\end{array}$ & $4.93 \pm 2.72$ & $4.26 \pm 2.34$ & 0.2970 \\
\hline $\begin{array}{l}\text { Duration } \\
\text { (weeks) }\end{array}$ & $13.04 \pm 3.48$ & $16.89 \pm 3.39 *$ & $p<0.01$ \\
\hline
\end{tabular}

Note: *Significant difference.

alone group and combined rTMS treatment group was $62.19 \pm 5.77$ and $63.50 \pm 7.97$, the SAS score was 66.07 \pm 9.43 and $64.89 \pm 8.38$, respectively, and there were no significant differences between the two groups. After treatment, the SDS score of BTX-A alone group and combined rTMS treatment group was $49.69 \pm 7.90$ and $49.46 \pm 6.73$, respectively, and there was no statistical difference between the two groups; after treatment, the SAS score of BTX-A alone group and combined rTMS treatment group was $53.88 \pm 7.34$ and $48.79 \pm 6.62$, respectively, and there was statistical difference between the two groups. These results showed that BTX-A alone treatment and combined rTMS treatment both significantly reduced the anxiety and depression of patients, but the improvement of anxiety after combined rTMS treatment was better (Table 4).

\section{Adverse Reactions of Treatment}

The most common adverse reactions of BTX-A injection were incompetence eyelid closure and blepharoptosis. Among the 63 patients enrolled in this study, none of them had such adverse reactions.

\section{Discussion}

The injection of BTX-A into orbicularis oculi muscle can significantly relieve the symptoms of BEB patients and has been used as an effective treatment method for BEB. ${ }^{9}$ Our 
Table 4 SDS and SAS Scores of the Patients Before and After Treatment

\begin{tabular}{|l|l|l|l|l|}
\hline \multirow{2}{*}{} & \multicolumn{2}{|l|}{ Before Treatment } & \multicolumn{2}{l|}{ After Treatment } \\
\cline { 2 - 5 } & $\begin{array}{l}\text { BTX-A } \\
\text { Group }\end{array}$ & $\begin{array}{l}\text { Combined } \\
\text { rTMS Group }\end{array}$ & $\begin{array}{l}\text { BTX-A } \\
\text { Group }\end{array}$ & $\begin{array}{l}\text { Combined } \\
\text { rTMS Group }\end{array}$ \\
\hline SAS & $\begin{array}{l}66.07 \\
\pm 9.43\end{array}$ & $64.89 \pm 8.38$ & $\begin{array}{l}53.88 \\
\pm 7.34^{*}\end{array}$ & $48.79 \pm 6.62^{\#, * *}$ \\
\hline SDS & $\begin{array}{llll}62.19 \\
\pm 5.77\end{array}$ & $63.50 \pm 7.97$ & $\begin{array}{l}49.69 \\
\pm 7.90^{*}\end{array}$ & $49.46 \pm 6.73^{\#}$ \\
\hline
\end{tabular}

Notes: $*_{p}<0.01$ for the comparison between after BTX-A treatment and before BTX-A treatment. ${ }_{p}<0.01$ for the comparison between after combined rTMS treatment and before combined rTMS treatment. $* * p<0.05$ for the comparison between combined rTMS treatment and BTX-A treatment.

clinical observation showed that BTX-A injection could be the best treatment method to improve the symptoms of BEB. ${ }^{3}$ However, many patients often have anxiety and depression. About $30-60 \%$ of BEB patients are accompanied by anxiety and depression. Our previous study reported that BTX-A treatment could significantly improve the anxiety and depression of BEB patients. ${ }^{3}$

In this study, we further explored the effect of BTX-A combined with TMS on the mood disorder in BEB patients accompanied by anxiety and depression. The results showed that SDS standard score decreased to normal level after BTX-A alone injection treatment, indicating that BTX-A treatment significantly improved the depression associated with blepharospasm. Botulinum toxin has been reported for the treatment of depression as early as 1994. ${ }^{10}$ In 2014, a randomized, double-blind, placebocontrolled trial of 74 patients showed that the injection of BTX into the corrugator supercilii and procerus could have a significant and lasting antidepressant effect on the patients with severe depression. ${ }^{11}$ In this study, our results showed that although the SAS score significantly decreased after BTX-A alone treatment, it was higher than 50 and the patients still had mild anxiety. After combined rTMS treatment, the average SAS score decreased to normal level, indicating that the anxiety of the patients was further improved. In addition, rTMS enhanced the efficacy of BTX-A and significantly prolonged the duration of symptom relief. It has been reported that rTMS could be used in the treatment of anxiety/ depression disorder, and low-frequency stimulation of the dorsolateral frontal lobe has a good effect on relieving anxiety/depression. ${ }^{12}$ Blepharospasm can cause mood disorder, and mood disorder can cause or aggravate blepharospasm, ${ }^{6}$ indicating that mood disorder and blepharospasm may have a common pathway in neuroregulation, but this needs further study.

$\mathrm{BEB}$ is one of the most common focal dystonias and the pathogenesis is still unclear. It is believed that BEB is related to the dysfunction of basal ganglia. The decline of substantia nigra-striatum- $\gamma$ aminobutyric acid (GABA) function leads to dopaminergic function inhibition and cholinergic hyperactivity, causing muscle overexcitation and blepharospasm. ${ }^{13}$ GABA and dopamine play an important role in individual mood regulation. ${ }^{14-16}$ BTXA inhibits the release of acetylcholine by specifically binding to the presynaptic membrane acetylcholine receptor, thereby reducing muscle excitability. ${ }^{17}$ In addition, a possible mechanism of botulinum toxin in the treatment of chronic migraine or severe depression is to regulate the central or peripheral neurotransmitters, such as 5-HT, substance P, GABA, and glutamic acid. ${ }^{18}$

TMS stimulates the dorsolateral prefrontal lobe, and regulates mood by regulating the function of prefrontallimbic network system. Low-frequency rTMS can inhibit nerve excitability, and direct stimulation of basal ganglia may regulate the basal ganglia-thalamus-frontal circuit, thereby improving the excitability of dopaminergic neurons in the substantia nigra reticular structure, increasing the inhibition of spinal trigeminal complex and reducing blink reflex. ${ }^{19}$ The former is aimed at the periphery and the latter is aimed at the central regulation. The combination of the two can achieve a better efficacy.

Nervous system diseases complicated with anxiety and depression are very common. On the one hand, the disease itself causes psychological burden to patients. On the other hand, many diseases may have the same molecular mechanism with mood disorder in terms of neuroregulation, which makes the patient's condition worse. TMS has been widely used in the treatment of nervous system diseases, including depression, anxiety, dyskinesia, and poststroke exercise rehabilitation. ${ }^{5}$ TMS has auxiliary curative effect and is safe without obvious side effects. Botulinum toxin is widely used in treating nervous system diseases, including dystonia and depression, and is the first-choice treatment method for blepharospasm. ${ }^{2}$ To our knowledge, this is the first study to combine BTX and TMS to treat BEB patients accompanied by depression and anxiety. In conclusion, compared to BTX-A alone treatment, BTX-A combined with rTMS can effectively improve the effect of BTX-A, prolong the duration of blepharospasm relief, and significantly reduce depression and anxiety. 


\section{Disclosure}

The authors report no conflicts of interest in this work.

\section{References}

1. Hallett M 1, Evinger C, Jankovic J, et al; BEBRF International Workshop. Update on blepharospasm: report from the BEBRF International Workshop. Neurology. 2008;71(16):1275-1282. doi:10.1212/01.wnl.0000327601.46315.85

2. Simpson DM, Hallett M, Ashman EJ, et al. Practice guideline update summary: botulinum neurotoxin for the treatment of blepharospasm, cervical dystonia, adult spasticity, and headache: report of the Guideline development subcommittee of the American Academy of Neurology. Neurology. 2016;86(19):1818-1826. doi:10.1212 WNL.0000000000002560

3. Dong H, Fan S, Luo Y, et al. Botulinum toxin relieves anxiety and depression in patients with hemifacial spasm and blepharospasm. Neuropsychiatr Dis Treat. 2018;15:33-36. doi:10.2147/NDT. $\mathrm{S} 181820$

4. Barker AT, Jalinous R, Freeston IL. Non-invasive magnetic stimulation of human motor cortex. Lancet. 1985;325(8437):1106-1107. doi:10.1016/S0140-6736(85)92413-4

5. Lefaucheur JP, André-Obadia N, Antal A, et al. Evidence-based guidelines on the therapeutic use of repetitive transcranial magnetic stimulation (rTMS). Clin Neurophysiol. 2014;125(11):2150-2206.

6. Gazulla J, García-Rubio S, Ruiz-Gazulla C, et al. Clinical categorization of psychogenic blepharospasm. Parkinsonism Relat Disord. 2015;21(3):325-326. doi:10.1016/j.parkreldis.2014.12.005

7. Fahn S, Bressman SB, Marsden CD. Classification of dystonia. $A d v$ Neurol. 1998;78:1-10. doi:10.1212/WNL.50.5_Suppl_5.S1

8. Cohen DA, Savino PJ, Stern MB, et al. Botulinum injection therapy for blepharospasm: a review and report of 75 patients. Clin Neuropharmacol. 1986;9(5):415-429. doi:10.1097/00002826198610000-00002

9. Tsoy EA, Buckley EG, Dutton JJ. Treatment of blepharospasm with botulinum toxin. Am J Ophthalmol. 1985;99(2):176-179. doi:10.1016/0002-9394(85)90228-4

10. Murry T, Cannito MP, Woodson GE. Spasmodic dysphonia. Emotional status and botulinum toxin treatment. Arch Otolaryngol Head Neck Surg. 1994;120(3):310-316. doi:10.1001/ archotol.1994.01880270056010
11. Finzi E, Rosenthal NE. Treatment of depression with onabotulinumtoxinA: a randomized, double-blind, placebo controlled trial. J Psychiatr Res. 2014;52:1-6. doi:10.1016/j.jpsychires.2013.11.006

12. Vicario CM, Salehinejad MA, Felmingham K, et al. A systematic review on the therapeutic effectiveness of non-invasive brain stimulation for the treatment of anxiety disorders. Neurosci Biobehav Rev. 2019;96:219-231. doi:10.1016/j.neubiorev.2018.12.012

13. Balint B, Bhatia KP. Isolated and combined dystonia syndromes - an update on new genes and their phenotypes. Eur J Neurol. 2015;22 (4):610-617. doi:10.1111/ene.12650

14. Peciña M, Sikora M, Avery ET, et al. Striatal dopamine D2/3 receptor-mediated neurotransmission in major depression: implications for anhedonia, anxiety and treatment response. Eur Neuropsychopharmacol. 2017;27(10):977-986. doi:10.1016/j. euroneuro.2017.08.427

15. Mazzei L, Ruiz-Roso MB, de Las Heras N, et al. Allicin neuroprotective effect during oxidative/ inflammatory injury involves AT1-Hsp70-iNOS counterbalance axis. Biocell. 2020;44 (4):671-681. doi:10.32604/biocell.2020.014175

16. Wang H, Fang F, Fang C, Zhao R, Wang S. Changes in neuropeptides related to food intake in the rat arcuate nucleus after chronic immobilization stress and the effect of comfortable music exposure. Biocell. 2020;44(3):421-429. doi:10.32604/biocell.2020.010257

17. Lee S, Park S, Lew H. Long-term efficacy of botulinum neurotoxin-A treatment for essential blepharospasm. Korean J Ophthalmol. 2018;32(1):1-7. doi:10.3341/kjo.2017.0030

18. Aaron RV, Fisher EA, de la Vega R, Lumley MA, Palermo TM. Alexithymia in individuals with chronic pain and its relation to pain intensity, physical interference, depression, and anxiety: a systematic review and meta-analysis. Pain. 2019;160(5):994-1006. doi:10.1097/ j.pain.0000000000001487

19. Kranz G, Shamim EA, Lin PT, et al. Transcranial magnetic brain stimulation modulates blepharospasm: a randomized controlled study. Neurology. 2010;75(16):1465-1471. doi:10.1212/WNL.0b013e3181f8814d
Neuropsychiatric Disease and Treatment

\section{Publish your work in this journal}

Neuropsychiatric Disease and Treatment is an international, peerreviewed journal of clinical therapeutics and pharmacology focusing on concise rapid reporting of clinical or pre-clinical studies on a range of neuropsychiatric and neurological disorders. This journal is indexed on PubMed Central, the 'PsycINFO' database and CAS, and is the official journal of The International Neuropsychiatric Association (INA). The manuscript management system is completely online and includes a very quick and fair peer-review system, which is all easy to use. Visit http://www.dovepress.com/testimonials.php to read real quotes from published authors. 